\title{
INVESTIGACIONES
}

\section{Procesos educativos de la comunidad wayuu en la educación superior: entre el ancestro y la modernidad}

\author{
Formative processes of the Wayuu community in higher education: \\ between the ancestor and modernity \\ Gilberto Bonilla Sánchez ${ }^{a}$, Roberto Alonso Cardona Ospina ${ }^{a}$, \\ Dénix Alberto Rodríguez Torres ${ }^{a}$ \\ ${ }^{a}$ Universidad Santo Tomás, Colombia. \\ gbonillasan@gmail.com, roalcaos@gmail.com,denixvirtual@gmail.com
}

\begin{abstract}
RESUMEN
El presente artículo es una reflexión sobre la experiencia educativa y pedagógica de un considerable grupo de jóvenes de la comunidad wayuu de la alta Guajira colombiana que adelanta sus estudios en diferentes disciplinas de educación superior en la universidad Santo Tomás. A partir de los relatos y entrevistas estructuradas aplicadas a los estudiantes, y desde el análisis categorial contenido en la matriz de estudio, se desarrolla un acercamiento a la experiencia académica y vivencial del grupo en estudio. Se evidencia la importancia que representa para cada miembro de la comunidad wayuu el acceso a un nivel de educación superior, traducido en oportunidad para su promoción personal y profesional.
\end{abstract}

Palabras claves: experiencia educativa, cosmovisión, culturas milenarias.

\begin{abstract}
This article is a reflection on the educational and pedagogical experience of a considerable group of young people from the Wayuu community of the upper Guajira region of Colombia who are pursuing their studies in different disciplines of higher education at Santo Tomás University. From the stories and structured interviews applied to the students and from the categorical analysis contained in the study matrix, an approach to the academic and experiential experience of the group under study was developed. The importance of the access to higher education for each member of the Wayuu community was demonstrated, translated into an opportunity for personal and profesional.
\end{abstract}

Key words: educational experience, worldview, millenary cultures. 


\section{El Principio}

Al comienzo, en medio del silencio, la quietud y la soledad, sólo existían Maleiya, el gran espíritu, el principio creador, Ziruma, el cielo, el espacio; Piushi, la obscuridad; y Mensh, el tiempo. Hizo, entonces, Maleiya al sol, la luna y las estrellas para que hubiera luz y claridad. Creó luego a Mma, la tierra; el agua y el aire para que hubiera vida. Y fue así que las aguas en su andar conocieron la tierra y se enamoraron de ella. Mostraron su poder con cielo oscurecido, truenos y relámpagos, primero unas lloviznas y al final se descargaron sobre ella para fecundarla. Decidió Maleiya el lugar por donde correrían los ríos y estaría el mar y para ellos creó a Pará, el espíritu del agua.

Y creó los vientos. Al aire lo puso a correr en distintas direcciones. Con ellos estaría Japirach, el viento del norte. Maleiya hizo después las plantas y los animales, dándole a cada cosa el espíritu que le correspondía para que hubiera movimiento. Todos ellos se bastaron por sí mismos y cumplieron su misión.

A las plantas les dio muchas formas y tamaños para que produjeran flores, frutos y semillas abundantemente. Y las colocó en todos los lugares de la tierra. A los animales también les proporcionó muchas formas, tamaños y colores. Les dijo que comer y a dónde ir.

Alfonso Forero, Nosotros los Wayuu.

\section{INTRODUCCIÓN}

La vida cultural Wayuu es el resultado de un largo proceso histórico de saber milenario, que condensa una forma de pensamiento y un modo de abordar el mundo en la relación histórica del entorno natural y ambiental del territorio ancestral donde se concibe el reconocimiento del valor sagrado de la vida en todas sus formas. Por lo anterior, la espiritualidad Wayuu se funda en el reconocimiento de una existencia espiritual en cada uno de los elementos que hacen parte del entorno natural del territorio ancestral, el cual comprende todo el ámbito de la península de la Guajira. Esta valoración de la vida espiritual se sitúa en los principios del sistema normativo, en cuya aplicación se reconoce el valor de la palabra y su amplia función social para el diálogo y la transmisión de conocimiento, el cual produce en la riqueza de la tradición oral de una generación a otra.

El punto de partida radica en un ejercicio cosmovisional como una manera de reconocer la riqueza inmaterial que encarna un pueblo wayuu que ha sufrido las vicisitudes del trasegar histórico de nuestros pueblos indígenas latinoamericanos, para llegar a la reflexión experiencial de su inserción en la educación superior y su impacto en la cultura misma.

Encontramos entonces un ligero abordaje a sus cosmovisiones respecto a: lo antropológico, teológico, sociológico, geográfico e histórico, en aras de disfrutar de las órbitas de su sabiduría ancestral, la comprensión de la vitalidad y su íntima relación con el medio.

Los procesos educativos siempre están encaminados al perfeccionamiento personal y colectivo, asunto visto de igual manera por los estudiantes wayuu que así lo expresan a lo largo del presente estudio. Alcanzar niveles de educación superior y profesionalización constituye un baluarte para los estudiantes que han contado con la fortuna de acceder a un nivel de educación superior si se tiene en cuenta las condiciones socioeconómicas, sostenidas por actividades de pastoreo, mediana agricultura, pesca y productos manufacturados como artesanías. Aunado a ello, las discretas condiciones de salud, desnutrición, abandono 
estatal, usurpación de los recursos económicos por la corrupción de sus líderes políticos, hacen de estas comunidades asentadas en la alta Guajira colombiana, un pueblo vulnerado permanentemente y amenazado, si se leen las altas tasas de mortalidad en niños menores de 5 años, asociadas a desnutrición y hambre, para un promedio de 38 muertes en el año 2018, según lo indica un artículo del diario el Espectador de Colombia, que data del 22 de septiembre de 2018.

Frente a este sombrío panorama, los estudiantes tienen sus profundas críticas al Estado y la sociedad colombianas, y se esfuerzan en prepararse soñando para su pueblo mayor equidad, reconocimiento, justicia social y oportunidades de superación como las que ellos han alcanzado.

\subsection{UNIDAD DE ESTUDIO}

No es normal en los contextos académicos regionales y pasillos universitarios encontrar hermanos indígenas, vistiendo orgullosos sus vistosos trajes y mantas. Al alma mater de la universidad santo Tomás (Colombia) desde el año 2010 han llegado los wayuu, representados por inquietos jóvenes aborígenes procedentes de la alta Guajira quienes se han matriculado para adelantar estudios en diferentes carreras.

La meta fue en cinco años portar sus togas y birretes y regresar a su región (Siapana) a aplicar sus conocimientos. Llegan gracias a una interesante experiencia de la que han sido pioneras varias universidades privadas de la región oriente de Colombia luego de ser elegidos por los líderes de los clanes 'eiruku' que rigen sus comunidades y representan la autoridad en el mundo wayuu.

Aunque han contado con importante acogida de la comunidad universitaria su proceso de adaptación no ha sido fácil, empezando por su indumentaria, las cuales han tenido que adecuar para el acceso a las clínicas y laboratorios para el caso de quienes han ingresado a programas de salud (odontología u optometría). En la cafetería, ellos en vez de consumir empanadas y alimentos de paquete, prefieren llevar su propio menú: el 'sawa' un alimento hecho con maíz tostado. Por otra parte, le tomaron el ritmo al estudio, resultando algunos de ellos aventajados frente a sus compañeros. Hablar en público, es algo difícil, si se considera el arraigo a su idioma nativo: el wayuunaiky. En su llegada a Bucaramanga, (Santander, Colombia) se ubicaron en un área rural, donde debían madrugar mucho para llegar a horas a sus clases, ahora con el tiempo, muchos optaron por tomar en arriendo habitaciones cercanas a sus sedes universitarias y asumir los costos.

Muchos de los estudiantes, no superan el semestre o el año y por diversas razones regresan a su tierra, no ha sido el caso de otros tantos como Cira Elena Navas (Estudiante de Derecho) quien ha superado muchos obstáculos entre ellos el económico y está próxima a graduarse como abogada de la universidad santo Tomás en Bucaramanga.

Expresaba Cira a Vanguardia Liberal en 2010 (Periódico local) su gran compromiso con su pueblo: "Aquí el compromiso es con nuestro pueblo, con nuestra gente. Quiero saber de leyes para poderle cantarles la tabla a los políticos que van a nuestra tierra a pedir votos, pero que jamás hacen algo por nuestra tierra”.

Como ya se ha anotado anteriormente, el estudio permite además de conocer referentes cosmovisionales, contrastar sus visiones de mundo con la experiencia académica y de aprendizajes durante su estancia en la universidad y el contexto sociocultural inmediato. 
PROCESOS EDUCATIVOS DE LA COMUNIDAD WAYUU EN LA EDUCACIÓN SUPERIOR: ENTRE EL ANCESTRO Y LA MODERNIDAD

\section{MÉTODO}

\subsection{CRITERIOS DE ANÁLISIS}

Dada la importancia del acercamiento cosmovisional con la comunidad Wayuu, dicho ejercicio se soporta desde las siguientes categorías y conceptos:

\begin{tabular}{|c|c|}
\hline Categorías & Subcategorías \\
\hline Antropología & $\begin{array}{l}\text { - Concepciones antropológicas } \\
\text { - Psicología } \\
\text { - Axiología } \\
\text { - Relaciones } \\
\text { - Organización familiar }\end{array}$ \\
\hline Teología & $\begin{array}{l}\text { - } \text { Concepción de lo divino } \\
\text { - Sistema de creencias } \\
\text { - Relación con lo divino } \\
\text { - Culto - ritos }\end{array}$ \\
\hline Sociología & $\begin{array}{l}\text { - Familia } \\
\text { - Sociedad } \\
\text { - Trabajo } \\
\text { - Legislación } \\
\text { - Cultura } \\
\text { - Política } \\
\text { - Estructura } \\
\text { - Sistemas de organización }\end{array}$ \\
\hline Geografía & $\begin{array}{l}\text { - Conciencia geográfica } \\
\text { - Topografía } \\
\text { - Historiografía }\end{array}$ \\
\hline Historia & $\begin{array}{l}\text { - Pasado } \\
\text { - Presente } \\
\text { - } \text { Futuro }\end{array}$ \\
\hline
\end{tabular}

Aunque los tópicos (categorías y conceptos) señalados puedan ampliarse, son éstos los que inicialmente permiten el acercamiento (cosmovisional) con las representantes de la comunidad Wayuu presentes en la Universidad Santo Tomás. 


\begin{tabular}{|c|c|c|}
\hline Categorías & Subcategorías & Preguntas \\
\hline Antropología & $\begin{array}{l}\text { - } \text { Concepciones Antropológicas } \\
\text { - } \text { Psicología } \\
\text { - } \text { Axiología } \\
\text { - } \text { Relaciones } \\
\text { - Organización Familiar }\end{array}$ & $\begin{array}{l}\text { 1. ¿Qué significa el ser humano para } \\
\text { Uds.? } \\
\text { 2. ¿Qué concepto tienen de las personas } \\
\text { externas a su etnia o familia? } \\
\text { 3. ¿Cuál es la importancia de organizarse } \\
\text { por castas? } \\
\text { 4. ¿Cómo es la organización jerárquica } \\
\text { de la comunidad Wayuu? }\end{array}$ \\
\hline Teología & $\begin{array}{ll}\text { - } & \text { Concepción de lo divino } \\
\text { - } & \text { Sistema de creencias } \\
\text { - } & \text { Relación con lo divino } \\
\text { - } & \text { Culto - Ritos }\end{array}$ & $\begin{array}{l}\text { 5. ¿Cuál es la idea de dios? } \\
\text { 6. ¿En qué y en quién creen? } \\
\text { 7. ¿Qué rituales llevan a cabo en la } \\
\text { comunidad? } \\
\text { 8. ¿De qué manera se relacionan con la } \\
\text { divinidad? } \\
\text { 9. ¿A quién rinden culto? }\end{array}$ \\
\hline Sociología & $\begin{array}{ll}\text { - } & \text { Familia } \\
\text { - } & \text { Sociedad } \\
\text { - } & \text { Trabajo } \\
\text { - } & \text { Legislación } \\
\text { - } & \text { Cultura } \\
\text { - } & \text { Estítica } \\
\text { - } & \text { Sistemastura } \\
\end{array}$ & $\begin{array}{l}\text { 10. ¿Qué concepto tienen de familia y } \\
\text { quiénes la integran? } \\
\text { 11. ¿Cómo conciben la sociedad? } \\
\text { 12. ¿Qué significado tiene el trabajo para } \\
\text { Uds.? } \\
\text { 13. ¿Cómo opera la ley, quién es la } \\
\text { autoridad y qué ocurre si se desacata? } \\
\text { 14. ¿Quiénes pueden ejercer la ley? } \\
\text { 15. ¿Cuál es su idea de justicia? } \\
\text { 16. ¿Qué los caracteriza y diferencia de } \\
\text { otras comunidades indígenas? }\end{array}$ \\
\hline Geografía & $\begin{array}{ll}\text { - } & \text { Conciencia geográfica } \\
\text { - } & \text { Topografía } \\
\text { - } & \text { Historiografía }\end{array}$ & $\begin{array}{l}\text { 17. ¿Cuál es su conciencia geográfica? } \\
\text { 18. ¿Qué significa para ustedes la Tierra? } \\
\text { 19. ¿De qué manera conocen la historia de } \\
\text { su pueblo? }\end{array}$ \\
\hline Historia & $\begin{array}{ll}\text { - } & \text { Pasado } \\
\text { - } & \text { Presente } \\
\text { - } & \text { Futuro }\end{array}$ & $\begin{array}{l}\text { 20. ¿Qué hechos relevantes podría destacar } \\
\text { de la historia de su pueblo? } \\
\text { 21. ¿Ustedes conciben un presente } \\
\text { temporal? } \\
\text { 22. ¿Cómo advierten el futuro de su } \\
\text { pueblo? }\end{array}$ \\
\hline
\end{tabular}




\subsection{TÉCNICA:}

Para el acercamiento cosmovisional se aplicará además de la matriz de doble entrada la entrevista estructurada (de 3 a 5 preguntas) previamente organizadas y estructuradas para evitar divagaciones en el diálogo.

\subsubsection{Precisiones Cosmovisionales}

A continuación, se comparten las respuestas ofrecidas por una de las participantes de la investigación como una muestra representativa del acercamiento cosmovisional de la comunidad wayuu.

-Fecha: Noviembre 09 de 2018

-Lugar: Universidad Santo Tomás (Bucaramanga)

-Hora de inicio: 7:00 am.

-Hora de finalización: 8:00 am.

-Entrevistado: Cristina Andrioli Epieyú

-Facultad: Derecho

-Edad: 18 años

-Comunidad: Wayuu

-Casta: Epieyú

\begin{tabular}{|c|c|c|}
\hline Categorías & Subcategorías & Preguntas \\
\hline Antropología & $\begin{array}{l}\text { - Concepciones } \\
\text { Antropológicas } \\
\text { - Psicología } \\
\text { - Axiología } \\
\text { - Relaciones } \\
\text { - Organización } \\
\text { Familiar }\end{array}$ & $\begin{array}{l}\text { 1. ¿Qué significa el ser humano para Uds.? } \\
\text { "Creemos en mareyva que es dios. El ser humano va de } \\
\text { acuerdo con lo que dios creó. En mi cultura son cerrados } \\
\text { con ideología sexuales. No nos hemos dejado colonizar". } \\
\text { 2. ¿Qué concepto tienen de las personas externas a su } \\
\text { etnia o familia? } \\
\text { "Convivimos con familias externas, se permite el vínculo, } \\
\text { los vemos como personas que aportan a la comunidad y los } \\
\text { vemos como gente que quieren cambiar cosas nuestras, } \\
\text { pero admitimos sólo lo que se puede mejorar". } \\
\text { 3. ¿Cuál es la importancia de organizarse por castas? } \\
\text { "Las castas representan las familias, el rico es el que más } \\
\text { tiene animales y que produzcan. Igualmente es reconocida } \\
\text { la familia que responde cuando hay conflictos." } \\
\text { 4. ¿Cómo es la organización jerárquica de la } \\
\text { comunidad Wayuu? } \\
\text { "Ya lo dije, por castas, familias grandes, papá, mamá, } \\
\text { hermanos, tíos, abuelos, etc. además los palabreros, que } \\
\text { normalmente son adultos hombres mayores". }\end{array}$ \\
\hline
\end{tabular}




\begin{tabular}{|c|c|c|}
\hline Teología & 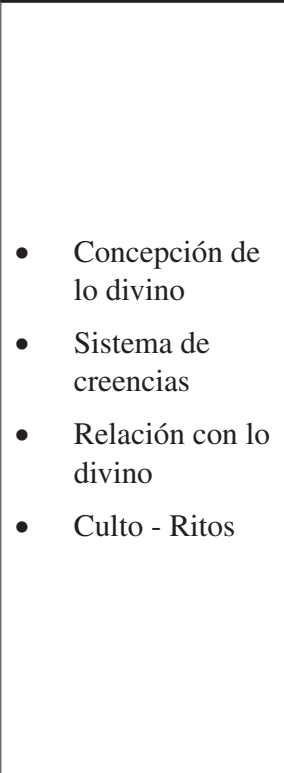 & $\begin{array}{l}\text { 5. ¿Cuál es la idea de dios? } \\
\text { "creemos en dios (Mareyva) único creador". } \\
\text { 6. ¿En qué y en quién creen? } \\
\text { "En mi cultura hay brujos (piachis) normalmente son mujeres. } \\
\text { Cuando quieren saber sobre algo, ellas se contactan con el más } \\
\text { allá, de acá abajo. Aprenden desde muy niñas. Creemos que el } \\
\text { alma se va después del segundo entierro". } \\
\text { 7. ¿Qué rituales llevan a cabo en la comunidad? } \\
\text { "Cuando se cree que va a pasar algo malo se hacen rituales con } \\
\text { yerbas. Si hay un accidente esconden a la persona un tiempo, } \\
\text { lo deciden los mayores. Si alguien muere asesinado para evitar } \\
\text { tragedias, los toman del lugar donde murió y lo entierran el } \\
\text { mismo día, lo pueden tomar sólo las mujeres. Las mujeres } \\
\text { hacen todo en los velorios". } \\
\text { 8. ¿De qué manera se relacionan con la divinidad? } \\
\text { "Nos relacionamos por medio de la naturaleza, aunque eso era } \\
\text { antiguamente, hoy asistimos a varias iglesias. Yo soy cristia- } \\
\text { na". } \\
\text { 9. ¿A quién rinden culto? } \\
\text { "Rendimos sólo culto a dios". }\end{array}$ \\
\hline Sociología & $\begin{array}{ll}\text { - } & \text { Familia } \\
\text { - } & \text { Sociedad } \\
\text { - } & \text { Trabajo } \\
\text { - } & \text { Legislación } \\
\text { - } & \text { Cultura } \\
\text { - } & \text { Política } \\
\text { - } & \text { Estructura } \\
\text { - } & \text { Sistemas de } \\
& \text { organización }\end{array}$ & $\begin{array}{l}\text { 10. ¿Qué concepto tienen defamilia y quiénes la integran? } \\
\text { "Significa la estructura de la sociedad cultural en que vivimos. } \\
\text { Todo Epieyú es mi familia". } \\
\text { 11. ¿Cómo conciben la sociedad? } \\
\text { "Como un grupo de personas estructuradas que hacen diversas } \\
\text { actividadesmos nustra cultura wuyunaiky en riesgo de } \\
\text { perderseer no tiene la firmeza del hombre.se sale de los parias. } \\
\text { Yo soy cristiana" dec". } \\
\text { 12. ¿Qué significado tiene el trabajo para Uds.? } \\
\text { "Los hombres pescan (vivo cerca al mar), las mujeres son } \\
\text { artesanas, hacen calzado y mochilas, etc.". } \\
\text { 13. ¿Cómo opera la ley, quién es la autoridad y qué } \\
\text { ocurre si se desacata? } \\
\text { "Se usa la palabra o el sistema oral, la autoridad son los } \\
\text { palabreros y ancianos. Si se sale de los parámetros se juzga y } \\
\text { castiga con nuestro sistema de leyes". } \\
\text { 14. ¿Quiénes pueden ejercer la ley? } \\
\text { "La ley la ejercen las autoridades como los ancianos y } \\
\text { palabreros". } \\
\text { 15. ¿Cuál es su idea de justicia? } \\
\text { "La justicia se aplica con la ley del talión. El palabrero hace el } \\
\text { papel de juez. Nace con la competencia de practicar. Hay } \\
\text { mujeres palabreras pero ha sido complicado, la mujer no tiene } \\
\text { la firmeza del hombre". } \\
\text { 16. ¿Qué los caracteriza y diferencia de otras } \\
\text { comunidades indígenas? } \\
\text { rSomos la capital indígena de Colombia. No estamos en } \\
\text { riesgo de perderse. Tenemos nuestra cultura wayuunaiky y } \\
\text { nuestra lengua wayuunaiky". }\end{array}$ \\
\hline
\end{tabular}




\begin{tabular}{|c|c|c|}
\hline Geografía & $\begin{array}{l} \\
\text { - } \quad \text { onciencia } \\
\text { - } \quad \text { geográfica } \\
\text { - Historiografía }\end{array}$ & $\begin{array}{l}\text { 17. ¿Cuál es su conciencia geográfica? } \\
\text { "Somos un pueblo situado en la alta guajira, en una tierra } \\
\text { muy rica en minerales, pesca, etc. Además muy } \\
\text { estratégica". } \\
\text { 18. ¿Qué significa para ustedes la Tierra? } \\
\text { "El territorio es algo que uno hereda. No puedo vivir } \\
\text { donde quiera. En mi comunidad, donde está solo se } \\
\text { establece la gente, pero a veces hay conflictos, ya que esas } \\
\text { tierras llegan a reclamarlas porque ahí vivieron los } \\
\text { abuelos". } \\
\text { 19. ¿De qué manera conocen la historia de su pueblo? } \\
\text { "Aprendemos en la familia la lengua y la forma de } \\
\text { vestirnos. Todo eso se aprende en el lugar y muchas otras } \\
\text { cosas en la escuela, donde nos inculcan el arraigo a } \\
\text { nuestra identidad. Mi mamá casi no me habla en español } \\
\text { sólo en wayuunaiky. Como yo salí a estudiar a Maicao, al } \\
\text { regresar se me olvidaban palabras. Podemos aprender otra } \\
\text { lengua como el inglés en otro momento, pero ¿wayuunaiky } \\
\text { cuándo?". }\end{array}$ \\
\hline Historia & $\begin{array}{ll}\text { - } & \text { Pasado } \\
\text { - } & \text { Presente } \\
\text { - } & \text { Futuro }\end{array}$ & $\begin{array}{l}\text { 20. ¿Qué hechos relevantes podría destacar de la } \\
\text { historia de su pueblo? } \\
\text { "Es una cultura que no se dejó colonizar, se mantuvo de } \\
\text { manera arbitraria y no se dejaron intervenir, esto nos da } \\
\text { un compromiso mayor con la cultura para preservarla". } \\
\text { 21. ¿Ustedes conciben un presente temporal? } \\
\text { "Sólo pensamos en el presente, en sembrar y cultivar } \\
\text { alimentos y esto hace que la gente se quede en un solo } \\
\text { lugar". } \\
\text { 22. ¿Cómo advierten el futuro de su pueblo? } \\
\text { "De eso se encargan los escritores, profesores y palabreros. } \\
\text { Hay Wayuu que nos les gusta ser wayuu. Los } \\
\text { especializados instruyen en la identidad cultural". }\end{array}$ \\
\hline
\end{tabular}




\section{RESULTADOS}

Una vez se ha realizado el ejercicio cosmovisional por medio de la entrevista estructurada emergen elementos cosmovisionales dignos de resaltar en este apartado.

Desde la perspectiva antropológica el humano se concibe como creatura hecha por dios (Mareyva). Existe una suerte de religación con lo divino muy importante: el humano está alineado a la creación divina. Sus principios están igualmente ordenados al trascendente, por tanto opciones sexuales distintas a la relación entre varón y mujer no son bien vistas; es posible decir que lo asocian a ideas venidas de fuera y en ellos cohabita el principio de pureza originaria cuando afirman ser un pueblo que históricamente se opuso a todo tipo de colonización.

Por otra parte, se muestran celosos de sus tradiciones y costumbres, por ello permiten la intervención de extraños en cuanto mejoren las cosas, pero si es para cambiarlas emerge la oposición. Con relación al sistema educativo y la forma como éste se concibe, se puede evidenciar que la formación que los hermanos wayuu reciben en las diferentes facultades a las que pertenecen, constantemente está siendo comparada y analizada desde sus tradiciones y costumbres con el propósito de acoger los elementos que las mejoren y reevaluar aquellos que consideran opuestos. Lo anterior ha enriquecido el debate que se propicia en los distintos espacios académicos de la universidad pues ha permitido a los demás integrantes de la comunidad académica conocer los aspectos que desde la cosmovisión wayuu se consideran opuestos a sus creencias y los argumentos que sustentan dicha oposición.

La estructura social de castas es muy importante en cuanto representan a las familias; el concepto de riqueza se asocia no sólo a quien tiene ganado, sino a aquellas familias que tienen la capacidad de responder cuando surgen conflictos en la comunidad. Se trasciende la idea de familia nuclear a familia extensa, con la presencia en algunas de ellas de los palabreros representados por adultos mayores que en su gran mayoría son hombres quienes ejercen dicha actividad en la comunidad.

Desde la perspectiva teológica es evidente una visión monoteísta, (Mareyva único creador). Es posible hallar en la comunidad los llamados piachis (brujos) ejercido en su mayoría por mujeres: cuando desean saber algo se comunican con el más allá "pero de acá abajo" anota la entrevistada. Podemos anotar cómo emerge un respeto particular por lo divino y lo dejan a los espíritus mundanos. Dicha actividad la aprenden las mujeres desde muy niñas; está clara la idea que el alma de los difuntos se va hasta el segundo entierro. Lo anterior hace parte de otras prácticas importantes como hacer riegos y ahuyentar las malas energías; el enterrar a una persona que ha muerto trágicamente el mismo día, hace parte de algunas prácticas asociadas a su imaginario y religiosidad, en ello tienen una participación activa las mujeres.

La naturaleza constituye un canal directo de comunicación con dios, al igual hoy muchos wayuu asisten a iglesias cristianas de diversa índole. Lo anterior ha permitido que desde el campo académico se pueden desarrollar ejercicios que conllevan a la implementación de pedagogías que propicien el diálogo inter-religioso y ecuménico donde los wayuu con sus tradiciones aportan argumentos a la discusión.

Desde el punto de la cosmovisional sociológico, para los Wayuu la familia constituye la estructura de la sociedad en la que están inmersos y no se reduce a una familia meramente nuclear, alude a la familia extensa, aquí expresa la entrevistada: “Todo Epieyú es mi 
familia" significando con ello que quien lleve su apellido está ligado familiarmente a ella y a su respectivo núcleo familiar. Las familias se dedican a diversas actividades, por ejemplo, los hombres se dedican a la pesca (o por lo menos quien viven cerca del mar) y la gran mayoría de las mujeres cultiva la tradición milenaria de las artesanías, elaborando mochilas y calzado, entre otros, en ello gastan buena parte de su tiempo y plasman su genio y talento.

Respecto a la figura de la autoridad y el sistema de leyes es liderado y ejercido por los ancianos y palabreros, quienes ejercen la autoridad en el territorio, si la situación delictiva ocurre fuera del territorio entra a operar la justicia ordinaria. Llama la atención el principio enunciado por la entrevistada: "La justicia se aplica con la ley del talión. El palabrero hace el papel de juez. Nace con la competencia de practicar. Hay mujeres palabreras pero ha sido complicado, la mujer no tiene la firmeza del hombre." De esta manera clara la idea de roles en la etnia wayuu pero a su vez la complementariedad de las acciones en conjunto: actividades definidas y tareas específicas que permiten dar cuenta de su organización más que de una condición netamente machista que desde el punto de vista de la misma entrevistada tiende a mejorarse con la formación profesional que ellas están recibiendo en la universidad.

A nivel geográfico, wayuu sabe de la riqueza de su tierra, por ello su conciencia geográfica es muy importante, denotando con orgullo las bondades de su territorio, rico en minerales, fauna acuática, pero también reconocen el valor estratégico de su territorio que los lleva a gozar de dichas zonas limítrofes y de frontera, inclusive a compartir su etnia en territorio venezolano, pero también saben las implicancias de situarse en un lugar aprovechado para ser corredor de contrabando, tráfico de drogas, presencia de grupos al margen a la ley, entre otros fenómenos sociopolíticos que constituyen un detrimento a esta bella región.

Para el indígena wayuu la tierra es algo heredado, no se puede vivir donde se quiera, se establecen en territorios legados por sus ancestros, ello no implica que haya eventuales conflictos de parte de familias que llegan a reclamar tierras que por alguna razón habían abandonado.

Finalmente, los aprendizajes vienen por vía familiar, allí aprenden la lengua y la manera de vestirse, en la escuela se les enseña el arraigo e identidad a su cultura. Es fundamental aprender el wayuunaiky antes que otras lenguas, como el inglés que se pueden aprender en otro momento como se relató en la entrevista. Por esta razón, los hermanos wayuu están constantemente en una dicotomía entre los saberes ancestrales que aprendieron de su familia y los saberes que se encuentran en la universidad.

Una categoría final abordada refiere a la historia. Como bien ocurre en la cosmovisión geográfica, lo histórico es motivo de orgullo, exaltan el que haya sido un pueblo resistente a la colonización arbitraria ejercida por los españoles. Este aspecto -dicen ellos- les conduce con mayor ahínco a preservar sus costumbres y cultura, que ha resistido desde tiempos milenarios.

La idea de tiempo en el pueblo wayuu se concentra en el presente, en sembrar y cultivar alimentos, lo que permite el establecimiento de las familias en un solo lugar (nomadismo), lo que permite la cohesión y la consolidación de las familias en el territorio.

Ante la pregunta cómo se advierte el futuro en la comunidad wayuu, la respuesta no se hace esperar, la entrevistada apunta que tanto los maestros, escritores y palabreros se encargan de perpetuar la cultura, porque a decir verdad hoy existen algunos waуии que no quieren ser wayuu, por ello los especializados tienen una gran labor allí de impulsar, infundir y preservar la cultura. 
Como se menciona antes, los datos recolectados en las entrevistas realizadas permiten evidenciar el mayor esfuerzo que los wayuu presentes en la Universidad Santo Tomás deben realizar de manera permanente al contrastar los saberes disciplinares de las distintas profesiones en las que se está formando con los tradiciones y costumbres de su comunidad. En palabras de J. Estermann (2016) la experiencia wayuu podría considerarse un buen ejemplo de lo que el autor considera un pluralismo epistemológico y metodológico que nos permita superar el reduccionismo de la academia dominante,

Esto significa construir y plantear epistemologías y metodologías contextuales (indígenas) que están en sintonía con los saberes ancestrales marginalizados. Puede significar la introducción de elementos orales, testimoniales, iconográficos, pero sobre todo simbólicos, ceremoniales, rituales y religiosos como recursos de un saber alternativo contextual con pretensión universal (o intervesal).

\section{DISCUSIÓN Y CONCLUSIONES}

Antes de empezar a comprender los fenómenos de la naturaleza los humanos tuvimos miedo del rayo y del trueno. Poco a poco se van explicando los fenómenos naturales y quedan atrás las primeras explicaciones míticas que dieron nuestros ancestros. Pero el conocimiento que se genera a espaldas de todas las tradiciones orales, y el cúmulo de saberes de comunidades primitivas, desconoce que tales saberes originales aportan valiosas comprensiones, interpretaciones, y cúmulo de experiencias que sumadas a otras comprensiones más actuales fortalecen las derivaciones que se puedan dar de las comprensiones de la vida con sus diferentes intuiciones y razones. Por la razón anterior el ejercicio cosmovisional a la etnia wayuu permite mayor conocimiento de tan importante familia, más aún constituye un acercamiento a la cultura, la educación y la idiosincrasia. En cada una de las líneas e ideas suscitadas por las entrevistas puede leerse el gran arraigo a sus costumbres y tradiciones ancestrales. A pesar de estar influenciados por cientos de aspectos externos como los medios de comunicación, el neoliberalismo, fenómenos sociopolíticos, modas, estilos alternativos de vida, entre otros, mantienen con firmeza sus principios, escalas jerárquicas, organización social y arraigo territorial.

Por tratarse de un ejercicio cosmovisional no se advierten en este documento acciones de tipo hermenéutico, sencillamente hay un ejercicio descriptivo a modo de acercamiento a las cosmovisiones en las categorías señaladas, donde se transmite su singular arraigo e identidad cultural. No así, se vislumbran actitudes, pensamientos, condiciones, emociones e imaginarios que los consolidan como pueblo ancestral de gran valía en el concierto de los pueblos indígenas de nuestra América. Su capacidad de resistencia y deseo perenne de mantener sus costumbres intactas frente a los embates del mundo exterior que laceran o buscan la vulneración de sus acervos históricos.

Queda planteada entonces la invitación a seguir indagando en sus cosmovisiones y maneras de ser y estar en el cosmos. Propugnar por su cuidado y preservación del legado cultural que representan para américa y el mundo. Constituyen un ejemplo de organización, de respeto y observación a la ley, de tesón, creatividad y constancia en sus empeños. Existe una gran deuda del pueblo venezolano y colombiano en reconocer y proteger en todo aspecto esta gran familia, víctima constante de perversas prácticas politiqueras y 
el desconocimiento estatal en sus necesidades básicas de salud, educación, protección, cuidado de la infancia. Para la educación de los ciudadanos, desde las diferentes maneras de habitar un espacio geográfico, es necesario aprender a trascender la idea de ver nuestros pueblos indígenas como algo típico e icónico que se puede mostrar a través de sus artesanías o bellos paisajes, tomarnos fotografías a su lado y exponerlas en redes sociales. Se necesita trabajar para que quienes ya no hacemos parte de las culturas ancestrales ayudemos, a través de la educación, a regresarles el estatus social y constitucional que como humanos y ciudadanos están construyendo todos los días.

Un desafío de la educación, y de los actores educativos, es ayudar a identificar y enriquecer las características socio-culturales de la comunidad wayuu desde las vivencias cotidianas y desde el contacto que ellos hacen con otras manifestaciones culturales. En palabras de Edgar Morin,

el propósito es crear un diálogo entre la fe y la incertidumbre. No estoy hablando de la fe religiosa, pues yo no tengo ningún credo, si no de la fe en los valores, en la posibilidad de mejorar las relaciones humanas, una fe en los valores de la fraternidad (Morin, 2010b, p. 130).

Para pensar hacia adelante hay por lo menos hay tres grandes retos que la educación necesita ayudar a leer críticamente para proyectar los saberes en un contexto de análisis vital: 1. Pensar desde la complejidad, porque la trama de la vida no se puede entender aislada sino en dinámica de red, de ligazón, de interdependencia. 2. Reconocer y valorar las identidades locales, porque somos hijos e hijas de un territorio, de una cultura concreta, de un contexto cargado de significados y de comprensiones vitales. 3. A partir de la complejidad, y de las identidades, ayudar a construir la comprensión de la existencia como fenómeno terrenal, desde el vitalismo cósmico reconocernos como auto-eco-organización, en concordancia con los desarrollos teóricos que aporta Edgar Morin y toda su escuela de pensamiento sistémico y complejo.

Contextualizando la experiencia de indagación con el pensamiento complejo se puede acotar que la inteligencia parcelada, compartimentada, mecanizada, disyuntiva y reduccionista desmenuza la complejidad del mundo en fragmentos disjuntos, fracciona los problemas, separa lo que está unido, "unidimensionaliza lo multidimensional". Es una inteligencia a la vez miope, présbita, daltónica, tuerta; por lo general acaba siendo ciega. Presupone la destrucción de todas las posibilidades de comprensión y de reflexión, eliminando así cualquier posibilidad de realizar un juicio correctivo o de tener una visión a largo plazo. Así, cuanto más multidimensionales se vuelven los problemas, más incapacidad hay de pensar su multidimensionalidad; cuanto más progresa la crisis, mayor es la incapacidad de pensar la crisis; cuanto más planetarios se vuelven los problemas, menos se piensa en ellos. Incapaz de pensar el contexto y la complejidad de lo planetario, la inteligencia ciega se vuelve inconsciente e irresponsable. Se ha transformado en un arma mortífera. (Morin, 2010a, p. 49).

Por ello urge desarrollar una primera actitud que promueva un conocimiento pertinente y empiece con el diálogo entre personas, comunidades, saberes, disciplinas, ciencias; un diálogo entre actores que se reconozcan como interlocutores. Esta disposición dialógica conduce al reconocimiento del ejercicio interdisciplinario que permite pensar a su vez el fenómeno humano y la realidad global desde lo planetario, lo continental, lo nacional y lo 
local. Porque los tiempos presentes exigen una reforma del conocimiento y una reforma al pensamiento que busque "relacionar los conocimientos entre sí, de relacionar las partes con el todo y el todo con sus partes". (Morin, 2011, p. 141)

Este diálogo de culturas y de saberes va mucho más allá de la tolerancia, porque con la justificación de la tolerancia se generan, también, grandes discriminaciones. El reto de la educación, y las culturas, nos exige mirar hacia la solidaridad de experiencias, de aprendizajes, conocimientos, valores y perspectivas de vida.

\section{REFERENCIAS BIBLIOGRÁFICAS}

Estermann, J. \& Tavares, M. (2015). Hacia una interversidad de saberes: Universidad e interculturalidad. Revista Lusófona de Educação, (31). ISSN 1646-401X. Disponível em: <http:// revistas.ulusofona.pt/index.php/rleducacao/article/view/5381>. Acesso em: 24 jan. 2019.

Forero, A. (1995). Nosotros los Wayuu. Fondo de Publicaciones. Universidad Distrital Francisco José de Caldas. Colombia: Bogotá.

Guerra, C. W. (2002). La Disputa y la palabra. La ley en la sociedad Wayuu. Ministerio de Cultura. Colombia.

Hurtado, J. (2012). Metodología de la investigación. Quirón (5ta ed.)

Ministerio de Justicia y del Derecho. (1997). Del olvido surgimos para traer nuevas esperanzas. La jurisdicción especial indígena. Imprenta nacional. Colombia.

Morin, E. (2010a). ¿Hacia el abismo? Globalización en el siglo XXI. Barcelona: Paidós. (2010b). Ma gauche. François Bourin Editeur. . (2011). La Vía para el futuro de la humanidad. Barcelona: Paidós.

Plan especial de Salvaguardia (PES) del sistema normativo Wayuu aplicado por el palabrero. (2013). Junta Mayor Autónoma de Palabreros. Ministerio de Cultura. Colombia.

Periódico Vanguardia Liberal. Febrero 28 de 2010. http://www.vanguardia.com/historico/54739ipregrado-wayuu

Periódico El Espectador. Colombia. Septiembre 22 de 2018. Disponible en: https://www.elespectador. $\mathrm{com} /$ noticias/nacional/38-ninos-han-muerto-por-desnutricion-en-la-guajira-durante-2018articulo-813782 
